\title{
OS CORPOS QUE (NÃO) IMPORTAM: USO DO DIREITO NA NORMALIZAÇÃO BIOPOLÍTICA DO GÊNERO A PARTIR DE UMA PERSPECTIVA FOUCAULTIANA ${ }^{1}$
}

\author{
THE BODIES THAT (DO NOT) MATTER: THE USE OF THE LAW IN THE BIOPOLITICAL \\ STANDARDIZATION OF THE GENDER FROM A FOUCAULTIAN PERSPECTIVE
}

\section{Isadora Forgiarini Balem}

Mestranda em Direitos da Sociedade em Rede pelo Programa de Pós Graduação em Direito da Universidade Federal de Santa Maria. Bolsista CAPES. Especialista em Direito de Família pela Pontifícia Universidade Católica do Rio Grande do Sul. Graduada em Direito pela UFSM. Pesquisadora do Núcleo de Direito Constitucional e integrante do grupo de pesquisa Direito e Gênero, ambos da UFSM.

E-mail: isadora.forgiarini@gmail.com

\section{Lucas Silva de Souza}

Mestrando do programa de pós-graduação em Direito da Universidade Federal de Santa Maria (UFSM) e bolsista CAPES. Especialista em Direito do Trabalho e Direito Processual do Trabalho pela Faculdade Damásio. Graduado em Direito pela Universidade Federal de Santa Maria (UFSM). Integra o grupo de pesquisa Centro de Culturas Jurídicas Comparadas (CCULTIS) e o grupo de pesquisa "Diálogo entre empresa y derecho constitucional: un análisis comparado de la responsabilidad social empresarial (colombia, francia y brasil) para proponer un proceso de gestión organizacional" vinculado à Universidade de Medellín na Colômbia.

E-mail: adv.lucasdesouza@gmail.com

\section{Valéria Ribas do Nascimento}

Pós-doutora pela Pontifícia Universidade Católica do Rio Grande do Sul (PUCRS); Doutora em Direito Público pela Universidade do Vale do Rio dos Sinos (UNISINOS), com período de pesquisa na "Universidad de Sevilla" (US); Mestre em Direito Público pela Universidade de Santa Cruz do Sul (UNISC); Graduada em Direito pela Universidade Federal de Santa Maria (UFSM); Professora do Programa de Pós-Graduação em Direito da UFSM; Professora Adjunta do Departamento de Direito da UFSM.

E-mail: valribas@terra.com.br

Recebido em: 01/07/2019

Aprovado em: 03/08/2020

RESUMO: Ao longo dos séculos, o controle político do estado sobre os indivíduos foi se alterando significativamente: da ostensividade de castigos físicos e suplícios às técnicas de controle cada vez mais sutis e eficientes. A problemática desse estudo se insere nas concepções foucaultianas de poder disciplinar e Biopolítica, sobretudo na ingerência estatal sobre os corpos e subjetividades a partir dos processos de normalização social operados na sexualidade humana. O presente artigo, por meio do método de abordagem dialético e utilizando-se dos métodos de procedimento histórico e bibliográfico, visa analisar de que forma a interpretação conservadora da sexualidade,

\footnotetext{
${ }^{1}$ O presente trabalho foi realizado com apoio da Coordenação de Aperfeiçoamento de Pessoal de Nível Superior -
} Brasil (CAPES) - Código de Financiamento 001. 
possibilitou a construção de categorias de normalidade e anormalidade, que atendam a fins econômicos e políticos. Permite concluir que, como consequência de tais instrumentos de poder e em decorrência da projeção de formas estanques de masculinidade e feminilidade - calcadas em um sistema binário-, há um endosso à opressão identitária, sob a alcunha da sexualidade "desviante", cuja implicação é a invisibilidade jurídica desses sujeitos, além da estigma social e a negação de uma existência digna por parte do Estado e do próprio sistema jurídico.

Palavras-chave: Biopolítica. Invisibilidade Jurídica. Opressão Identitária. Poder disciplinar. Sexualidade.

\begin{abstract}
Over the centuries, the political control of the state over individuals has changed significantly: from the ostensiveness of physical punishment and tortures to increasingly subtle and efficient control techniques. The problematic of this study is inserted in the Foucaultian conceptions of disciplinary power and Biopolitics, mainly in the state interference on the bodies and subjectivities from the processes of social normalization operated on human sexuality. Thus, the present article, through the method of approach dialectical approach and using historical and bibliographic procedures methods, aims to analyze how the conservative interpretation of sexuality has made it possible to construct categories of normality and abnormality that serve the purposes economic and political. It concludes that, as a consequence of such instruments of power and because of the projection of watertight forms of masculinity and femininity - based on a binary system - there is an endorsement of identity oppression, under the nickname of "deviant" sexuality, whose implication is the legal invisibility of these subjects, besides the social stigma and the denial of a dignified existence on the part of the State and the legal system itself.
\end{abstract}

Keywords: Biopolitics. Disciplinary power. Legal invisibility. Oppression of identity. Sexuality.

SUMÁRIO: Introdução. 1. Do poder disciplinar à biopolítica: o poder e o controle sob a ótica foucaultiana. 1.1 Direito como instrumento de poder e a disciplina como técnica de normalização dos corpos. 1.2 A inscrição da sexualidade como marca de poder: a construção da Biopolítica. 2. A cisnormatividade como Biopolítica de gênero: invisibilidade jurídica de corpos não binários. 2.1 A construção de uma Biopolítica de gênero calcada em binarismos jurídicos. 2.2 (In) Visibilidade jurídica dos corpos que (não) importam. Conclusão. Referências.

\title{
INTRODUÇÃO
}

A riqueza da obra de Michel Foucault está principalmente na profundidade da análise e na sagaz crítica destinada às estruturas sociais que nos cercam, sobretudo quanto aos arcabouços invisíveis que se reproduzem de forma silenciosa, naturalizando construções históricas e se constituindo em um locus de saber-poder que se retroalimentam indefinidamente.

Pretende-se compreender, a partir de diversas obras do filósofo francês, a construção de redutos de poder sustentados pela intervenção político-econômica na sexualidade humana. Assim, o presente artigo visa investigar de que forma a normalização das práticas sexuais e, por consequência, a própria inteligibilidade social do sujeito, foi afetada pelas técnicas de controle humano oriundas do poder disciplinar e da Biopolítica.

Para tanto, o estudo será estruturado em dois capítulos, ambos subdivididos em dois subcapítulos: no primeiro (1.1), abordar-se-á a emergência de um poder disciplinar, no qual a norma forjou padrões sociais de normalidade ao instrumentalizar o indivíduo, destinando-o a uma finalidade útil e sancionando os destoantes. Posteriormente (1.2), tratar-se-á sobre como a incidência de alguns fatores alteraram a dinâmica social e a forma de exercício do poder foi reestruturada a fim de atingir maior amplitude: o controle da população, dando origem à 
Biopolítica. Nesse contexto, o sexo foi inserido como espectro de poder, incidindo sobre ele diversas práticas normalizadoras, prescrições jurídicas e, sobretudo, interdições.

No segundo capítulo, discorrer-se-á sobre a opressão social erigida em torno de um sistema sexual binário, permeado por prescrições jurídicas que hierarquizam sujeitos em razão de uma "normalidade" artificialmente construída, influenciando na formação identitária dos sujeitos, mormente aqueles que não se enquadram na binariedade de gênero socialmente admitida (2.1). Por fim, estudar-se-á a estigmatização social e, por conseguinte, a invisibilidade dos corpos destoantes, a quem a recusa de submissão a um padrão binário de gênero acarreta na negação da sua constituição como sujeito de direitos e toda a dignidade que lhe deveria ser correlata (2.2).

Dessa forma, utiliza-se o método de abordagem dialético - na medida em que serão confrontadas as técnicas de controle de corpos face à desconstrução do discurso histórico e intencionalmente orientado para sustentar uma hierarquia sexual - e o método de procedimento monográfico, combinando-se técnicas de pesquisa bibliográfica.

\section{DO PODER DISCIPLINAR À BIOPOLÍTICA: O PODER E O CONTROLE SOB A ÓTICA FOUCAULTIANA}

"O poder está em Toda parte; não porque englobe tudo e sim porque provém de todos os lugares. O poder não é uma instituição e nem uma estrutura, não é uma certa potência de que alguns sejam dotados: é o nome dado a uma situação estratégica complexa numa sociedade determinada”. (FOUCAULT, 1988, p. 88/89).

A trajetória da humanidade é marcada por inúmeros acordos realizados entre indivíduos e o Estado. Conscientes da necessidade de ultrapassar o estado de natureza em que viviam - cuja guerra permanente e autotutela eram realidades intransponíveis - os sujeitos cedem parte de sua liberdade em troca da prometida segurança. Emerge, pois, o Estado de Direito, o qual passa a reunir o poder, anteriormente disperso, na figura única do soberano, implicando no fim do estado natural e início do Estado social e político.

Para que o Estado se realize efetivamente (e não seja simplesmente estabelecido), além da concretização dos seus efeitos jurídicos, impõe-se a busca pela sua eficácia, obtida pelo reconhecimento social do poder que dele emana. Poder que, nesse estudo, será abordado sob a ótica de Michel Foucault e suas imbricações com o Direito ${ }^{2}$, a partir da percepção daquele como algo microfísico ${ }^{3}$, eis que calcado em um controle sutil e meticuloso, com a finalidade de forjar uma sociedade normalizada e normalizadora, cujos desdobramentos impactam na construção da subjetividade moderna.

Ganham relevo as formas de demonstração do poder estatal ao longo dos séculos, cujo exercício se vincula, diretamente, aos diversos modelos assumidos pelo Estado e, concomitantemente, ao uso do Direto nessa empreitada. Destarte, por exemplo, a estruturação das monarquias se deu a partir de princípios de direito, implicando historicamente na "representação jurídico - discursiva do poder, cujo ponto central é a enunciação da lei” (FONSECA, 2012, p.

\footnotetext{
${ }^{2}$ Nesse ponto, insta salientar que, em que pese o autor não tenha escrito uma obra sobre o poder e, tampouco, uma teoria sobre o Direito, essas questões atravessam a maioria dos seus escritos, ainda que de modo indireto. Conforme Fonseca (2012, p. 22): “Não há unidade no objeto ‘direito’ em Foucault. Menos ainda o desenvolvimento de uma teoria ou um pensamento sistemático sobre o tema. O direito de que trata em diversos momentos de seus trabalhos não é sempre a mesma coisa e não remete a uma realidade em que se permite identificar traços gerais e recorrentes". Ainda, na mesma obra, Fonseca (2012, p. 35/37) chama a atenção para abordagem não essencialista do Direito por Foucault, enfatizando a sua dimensão histórica, haja vista que serviria para qualificar práticas normativas, de coação e sanção social, além de prática política e de racionalidade.

De acordo com Foucault (1979, p. 193): “O poder deve ser analisado como algo que circula, ou melhor, como algo que só funciona em cadeia. Nunca está localizado aqui ou ali, nunca está nas mãos de alguns, nunca é apropriado como uma riqueza ou um bem. O poder funciona e se exerce em rede".
}

Revista de Direito Brasileira | Florianópolis, SC | v. 26 | n. 10 | p. 5-24 | Mai./Ago. 2020 
98/103). Nesse momento histórico, verifica-se a existência de um modelo jurídico, no qual o poder é descrito em termos de interdição, e se manifesta principalmente por meio da lei, que determina o lícito e o ilícito .

Embora o poder monárquico absoluto fosse caracterizado pelas arbitrariedades travestidas na forma de privilégios, exceções e caprichos - e na manutenção de um status quo, sua sustentação aos olhos do povo se dava como aparente sistema de direitos, de modo que os mecanismos de poder e dominação eram postos em prática na figura do Direito (FOUCAULT, 1988, p. 83/85). Emerge, pois, uma ligação entre a lei e uma forma específica de poder: a soberania.

Entretanto, a partir da racionalidade advinda do Iluminismo, aliada ao crescimento do poder burguês e a emergência dos valores capitalistas, foram inauguradas novas formas de dominação social e poder, adequadas às regras de mercado que se anunciavam. A ostensividade dos castigos públicos ${ }^{4}$ contra infratores por parte do Estado cede espaço a formas de sujeição mais dissimuladas e, consequentemente, mais eficazes (POGREBINSCHI, 2004, 180).

Dessa forma, instrumentos - como o Direito e o próprio Estado - foram historicamente utilizados para moldar comportamentos aceitáveis em uma sociedade ${ }^{5}$, eis que integram uma "racionalidade de poder que se exercita em cada corpo, em cada ação, em cada pensamento, refletindo a capilaridade do poder, reconhecendo-se o papel de ambos nas diferentes formas de dominação". (SIQUEIRA; BIGOLIN NETO, 2015, p. 3).

\subsection{Direito como instrumento de poder e a disciplina como técnica de normalização dos corpos}

O Estado Moderno nasce sob os auspícios de uma nova forma de poder, denominado disciplinar, eis que inaugura uma lógica da sujeição, cuja finalidade é a utilização útil e dócil da capacidade humana (FOUCAULT, 2010, p. 134). ${ }^{6}$ Nesse contexto, compreende-se a disciplina como uma tecnologia positiva de exercício do poder, desenvolvido por meio de um conjunto de táticas, constituindo-se um mecanismo estratégico a partir do qual se estabelecem as relações de poder (FONSECA, 2012, p. 153). Emerge então o cerne da microfísica do poder, porquanto seu exercício se dá a partir da vigilância permanente, e não mais pela exclusiva vontade do soberano.

A essência desse poder é verificada pelo seu empenho no adestramento das pessoas, bem como na produção de sujeitos com determinadas habilidades (SIQUEIRA; BIGOLIN NETO, 2015, p. 8). A disciplina "fabrica indivíduos; ela é a técnica específica de um poder que toma os indivíduos ao mesmo tempo como objetos e como instrumentos de seu exercício" (FOUCAULT,

\footnotetext{
${ }^{4}$ Para Fonseca (2012, p. 123/124), a lei que, na forma de sentença, é executada minunciosamente diante de um público atento, principal alvo e personagem do ritual político constituído pelo suplício [...] O que está em jogo nesse modo de punição é uma economia de poder, o poder soberano, cujo funcionamento se atrela ao jogo entre um comando e uma sanção. O suplício se constitui numa mecânica de poder, em que a lei vale como a vontade do soberano, e a força da lei é sua própria força. Daí a função desse modo de punição ser uma forma jurídico-política: ele reativa o poder, na medida em que manifesta publicamente o triunfo da lei sobre qualquer forma de desobediência ao que prescreve" ( $p$. 127).

${ }^{5}$ De acordo com Fonseca $(2012$, p. 98), as razões da aceitação de tal modelo jurídico de poder seriam táticas e históricas. "Tática, pois a identificação do poder a um puro limite à liberdade mascararia aspectos essenciais de seu funcionamento e sua abrangência, tornando as condições de sua aceitação mais facilmente preenchidas. Por outro lado, as razões de ordem histórica remeteriam ao desenvolvimento das monarquias e Estados no final da Idade Média. Tais instituições organizavam-se sob o fundo de poderes locais e díspares, conflituosos, ligados à dominação da terra e a todas as formações nela implicadas (a servidão, os laços de suserania e vassalagem). “

${ }^{6}$ Para Agamben (2004, p. 13), os Estados modernos constituem-se na intersecção entre o jurídico e político, entre a ordem jurídica e a vida, como um "patamar de indeterminação entre democracia e absolutismo". Neste sentido o estado de exceção é "paradigma de governo da política contemporânea" e tem total e direta relação com a biopolítica ao decidir sobre a vida, sobre o valor de cada vida, sobre quem fazer viver e deixar morrer. Sendo assim, não se sobrepõe ou está alheio a ordem jurídica, está inerentemente conectado a ela. O estado de exceção torna-se a regra, não se coloca como medida excepcional, mas como paradigma de governo (2004, p. 18). É a "tentativa de incluir na ordem jurídica a própria exceção, criando uma zona de indiferenciação em que fato e direito coincidem” (2004, p. 42).
}

Revista de Direito Brasileira | Florianópolis, SC | v. 26 | n. 10 | p. 5-24 | Mai./Ago. 2020 
2010, p. 195). Não há que se olvidar, portanto, que tal poder disciplinar está inserido numa ambição econômico- política de controle, estabelecido por meio da homogeneização de condutas, da criação de standards de comportamento e da constituição de um estado de normalidade.

Fonseca (2012, p. 171) aduz que a disciplina pode ser entendida como uma tecnologia que tem nos corpos dos indivíduos "seu objeto privilegiado de investimento, com o fim de formar neles, e a partir deles, um 'tecido de hábitos' pelo qual é definida sua pertença a uma sociedade qualquer. E a este 'tecido de hábitos' pode-se dar o nome de "norma"'. Com o poder disciplinar nasce, consequentemente, o poder da norma, que ocupa a função desempenhada pela lei no paradigma da soberania: a codificação dos comportamentos cede espaço à normalização das condutas (POGREBINSCHI, 2004, p.194). Ao redor das noções de norma e normalização, são reunidas uma gama de estados e situações que se vinculam ao exercício do poder disciplinar "produtor de condutas, gestos, discursos ${ }^{7}$, subjetividades", de modo que a norma se constitui a forma como o exercício desse poder é possível. (FONSECA, 2012, p. 90).

Há uma modificação no paradigma histórico, na medida em que a técnica passa a ser utilizada - em detrimento do Direito - como instrumento de exercício do poder, e a lei dá lugar à normalização (POGREBINSCHI, 2004, 187). De acordo com Fonseca (2012, p. 99), esses novos mecanismos, formados ao longo dos séculos XVII e XVIII, "funcionavam pela técnica, pela normalização e pelo controle, mais do que pelo Direito, pela lei ou pelo castigo [...] não sendo possível, portanto, sua descrição e análise segundo a representação jurídico-discursiva do poder". ${ }^{8}$ Assim, à transmutação dos indivíduos em corpos dóceis, dá-se o nome de "processos de normalização social", a fim de que todos se adequem à norma, pois, conforme a hipótese foucaultiana, o estabelecimento do sistema jurídico advém diretamente do poder disciplinar (ESTEVES, 2014, p. 300).

Há que se ressaltar, porém, que a norma para Foucault não significa a regra jurídica stricto sensu. Com efeito, a norma representa uma tecnologia positiva de poder, na qual "normalizar significa agenciar a produção de condutas esperadas" (FONSECA, 2012, p. 88). Para além da classificação dos sujeitos em dadas categorias, a norma é um mecanismo de constituição do indivíduo. A norma, nesse contexto, faz referência ao normal: denota a construção de um arquétipo de conduta que guiará a avaliação daqueles que estão em harmonia com a norma, os normais, e aqueles que se afastam da norma, os anormais (FONSECA, 2012, p. 83).

A normalização disciplinar é o produto de um conjunto de procedimentos precisos, iniciado com a análise minuciosa dos indivíduos, decompostos em lugar, tempo, gestos, etc. Em um segundo momento, a disciplina qualifica os elementos analisados de acordo com finalidades pré-estabelecidas. Posteriormente, fixa procedimentos de adestramento e de controle permanentes (FONSECA, 2012, p. 208). Essa sequência, quando verificada, divide as pessoas entre "normal" e "anormal", a partir de um modelo de referência, fornecido pela norma e elaborado em razão de certo resultado esperado. Logo, é por meio do controle direcionado aos espaços institucionais ${ }^{9}$ que os mecanismos de normalização disciplinar se tornam possíveis. (FONSECA, 2012, p. 120).

\footnotetext{
${ }^{7}$ Conforme Tamsin Spargo (2017, p. 52), na teoria foucaltiana discurso não é apenas sinônimo de "fala", mas assume o conceito de uma "prática material situada historicamente que produz relações de poder. Os discursos existem dentro das instituições e dos grupos sociais, dão suporte a eles, e estão ligados a saberes específicos".

${ }^{8}$ É, por consequência, a norma e não a lei que interessa particularmente a Foucault nesse ponto, eis que sua principal finalidade não é esmiuçar a normatividade da lei e sua eventual conformidade com o objetivo justo, mas averiguar tal dimensão enquanto instrumento de normalização (FONSECA, 2012, p. 145). Assim, existe uma diferença, em Foucault, entre o caráter normativo da lei (a normatividade) e a normalização: enquanto a primeira se refere sempre aos limites e interdições (plano do dever-ser, numa concepção Kelseniana), a normalização se refere ao estabelecimento de médias ou medidas ideais (plano do ser ser) (p. 149).

${ }^{9}$ De acordo com Fonseca (2012, p. 180), as instituições disciplinares se orientam para a constituição de redes que formarão uma sociedade disciplinar. A fórmula dessa generalização é dada pelo dispositivo panóptico, como vetor de formação da sociedade disciplinar. [...] O modelo panóptico - composto por uma visibilidade absoluta e a incomunicabilidade controlada - abole as massas compactadas em favor da distribuição e da ordenação de individualidades separáveis, foi utilizado essencialmente nas prisões e, posteriormente teve sua lógica alargada para Revista de Direito Brasileira | Florianópolis, SC | v. 26 | n. 10 | p. 5-24 | Mai./Ago. 2020
} 
Para a efetivação do poder disciplinar também é imprescindível a individualização dos que lhe são submissos, a fim de que se possa "medir os desvios, determinar os níveis, fixar as especialidades e tornar úteis as diferenças" (FOUCAULT, 2011, p. 176/7) de valor entre o normal e anormal e, desta forma, comparar, hierarquizar, dar-lhes à devida destinação e, por fim, excluir quaisquer sinais destoantes por meio da sanção normalizadora, legitimada pelo sistema jurídico (SIQUEIRA; BIGOLIN NETO, 2015, p. 10/11).

Nesse contexto, modificam-se também as formas de punição, as quais passam a ter o objetivo de conferir utilidade à existência humana por meio da correção de comportamentos desviantes, ao tempo em que valorizam os indivíduos que se amoldam aos padrões definidos. A sanção normalizadora é destinada, precipuamente, à criação de hábitos através da prática reiterada de determinada condutas, cuja correção é direcionada aos processos de normalização, afastando-se da sanção punitiva anteriormente utilizada por meio dos suplícios (FONSECA, 2012, p. 175).

Observa-se então que a sociedade disciplinar cria uma massa indistinta de "prisioneiros da liberdade", assegurada pelo Direito enquanto compatibilizador de liberdades e limites. Destarte, o gozo da liberdade é garantido apenas quando condicionado à obediência dos padrões, sob pena de sofrer medidas disciplinares (SIQUEIRA; BIGOLIN NETO, 2015, p. 9). Nesse contexto, foram utilizados conhecimentos técnicos, a exemplo da medicina, para a disseminação de estigmas, inclusive biológicos, daqueles indivíduos em desconformidade com o padrão.

Após o estabelecimento das fronteiras entre os "normais" e os "anormais" no cerne do conhecimento e das práticas psiquiátricas, a disseminação das tecnologias de poder da normalização atingem todos os outros setores sociais (FONSECA, 2012, p. 92). Ao classificar, especificar e distribuir os indivíduos em relação a uma norma, a disciplina propõe uma hierarquia baseada na desqualificação de uns comparados aos outros, instituindo, deliberadamente, assimetrias entre os indivíduos (FONSECA, 2012, p. 183).

O poder disciplinar se vale, pois, da vigilância constante, da atribuição de patologias ao que classifica como anormal e da exclusão do diferente para garantir que a norma seja observada. Dessa forma, o Estado de Direito - por meio da norma - domina e sujeita os indivíduos na forma de produção da normalidade. E, por conseguinte, a sociedade de normalização ambiciona que "os procedimentos de normalização colonizem cada vez mais os da lei” (FOUCAULT, 1979, p. 106). Logo, o padrão de normalidade constitui a norma. Nesse sentido, Wolkmer (2006, p. 13) afirma que toda sociedade busca garantir uma "determinada ordem social, instrumentalizando normas de regulamentação essenciais, capazes de atuar como sistema eficaz de controle social. Constata-se que, na maioria das sociedades remotas, a lei é considerada parte nuclear de controle social".

O Direito surge como um dever-ser fundamental que orienta a concretização da vida dos indivíduos por meio de dois pressupostos: a disciplina - como conjunto de práticas para docilização dos corpos - e a determinação do que é socialmente inteligível. (MARTINS, 2012, p. 16/18). E, por conseguinte, ao institucionalizar as normas e torná-las cogentes, o Direito gera, concomitantemente, indivíduos que - em razão de suas condutas e modos de ser - são coletivamente considerados como inúteis, contraproducentes ou, nos termos de Butler (2017), "abjetos" e, por conseguinte, não merecem respaldo desse mesmo sistema jurídico. O principal desdobramento dessa tecnologia de poder, de acordo com Fonseca (2012, p. 176), é o êxito em forjar uma individualidade "marcada pela docilidade e pela utilidade, a constituição de um indivíduo normalizado e, enquanto tal, impossibilitado de ser sujeito autônomo".

diversas outras instituições que também visam o controle dos indivíduos, a exemplo de escolas, fábricas, manicômios. “O Panóptico permite, assim, uma sujeição real, sem o recurso da força e apenas pela forma como distribui os indivíduos em seu interior” (p. 181). 


\subsection{A inscrição da sexualidade como marca de poder: a construção da Biopolítica}

Com a inauguração do século XVIII houve modificações sociais - sobretudo no que tange ao crescimento exponencial da população- que impactaram diretamente nas formas de controle anteriormente desenvolvidas. E, em razão da relação direta entre a eficácia do pode disciplinar e a percepção da individualidade dos corpos - ao conformá-los e lhes conferindo identidades possíveis de acordo com a norma - verificou-se a insuficiência desta forma de disciplina diante da multiplicação do objeto. De tal modo, com as modificações introduzidas pelo fenômeno populacional, se fez necessária a remodelação das técnicas de poder, a fim de que se mantivesse o controle, expandindo seu alcance com o escopo de potencializar outros resultados que não (apenas) a obediência da norma. A partir disso, foram incluídos nas técnicas de controle os fenômenos que lhe eram correlatos, e suas variáveis próprias, a exemplo de taxa de natalidade, morbidade, esperança de vida, fecundidade, estado de saúde, incidência das doenças, forma de alimentação e de habitat (FOUCAULT, 1988, p. 130).

Surge então uma "arte de governo", denominada Biopolítica, que visa reorientar as práticas estatais a fim de incluir a população, a partir de suas características biológicas, em seus objetivos políticos (GUIZZO; INVERNIZZI, 2012, p. 122). ${ }^{10}$ A Biopolítica, ao invés de se dedicar aos indivíduos, amplia seu intento de influência e se detém em elementos que interferem na massa de indivíduos, visando a homogeneização dos discursos disciplinadores a partir do controle populacional: os processos reprodutivos, deslocamentos, mortandade, nutrição, etc. O controle se desloca do indivíduo para a espécie humana, possuindo aptidões de abrangência ainda mais significativas. ${ }^{11}$ Nesse aspecto, o biopoder, oriundo da Biopolítica, pode ser definido como:

A Biopolítica - enquanto técnica de poder verificada em todas as camadas sociais e utilizada por instituições e saberes variados (a exemplo da família, Exército, escola, polícia, medicina individual ou a administração das coletividades) - representou significa alteração no paradigma controlatório pela sua potencialidade de influir a nível macro: nos processos econômicos serviu como fator de segregação e de hierarquização social, permitindo a manutenção das formas de dominação (FOUCAULT, 1988, p. 131/2). Desse modo, a compreensão da Biopolítica enquanto técnica se associa, indiscutivelmente, ao avanço do sistema capitalista, na medida em que ela foi elemento indispensável deste ao permitir uma expansão inimaginável do controle, com a promoção de lucro por meio da inserção controlada dos corpos no sistema de produção e através da adequação dos fenômenos populacionais à economia. E o poder soberano antigamente refletido na forma de castigos físicos ostensivos e posteriormente modificado pela vigilância contínua - é agora sutilmente camuflado sob a administração calculista dos corpos e da sua potencialidade econômica, por meio de mecanismos contínuos, reguladores e corretivos.

Nesse contexto, no âmago das questões econômicas e políticas da população se encontra o sexo ${ }^{12}$, eis que passa a ser indispensável avaliar a taxa de natalidade, a idade do casamento, os

\footnotetext{
${ }^{10}$ Impende ressaltar que disciplina e biopolítica não são campos excludentes e sim complementares, atuando em níveis diferentes da sociedade, com o escopo comum de efetuar o controle dos corpos.

11 " [...] a disciplina tenta reger a multiplicidade dos homens na medida em que essa multiplicidade pode e deve redundar em corpos individuais que devem ser vigiados, treinados, utilizados, eventualmente punidos. E, depois, a nova tecnologia, que se instala e se dirige à multiplicidade dos homens, não na medida em que eles se resumem em corpos, mas na medida em que ela forma, ao contrário, uma massa global, afetada por processos como o nascimento, a morte, a produção, a doença etc. (...) Depois da anátomo-política do corpo humano, instaurada no decorrer do século XVIII, vemos aparecer, no fim do mesmo século, algo que já não é uma anátomo-política do corpo humano, mas que eu chamaria de "biopolítica" da espécie humana" (FOUCAULT, 1999. p. 289).

${ }^{12}$ Para FOUCAULT (1988, p. 78), o termo sexualidade apenas faz sentido dentro do paradigma cientificista ocidental, inaugurado com a modernidade. Como adverte: "A sexualidade é o correlato dessa prática discursiva desenvolvida lentamente, que é a scientia sexualis. As características fundamentais a essa sexualidade não traduzem uma representação mais ou menos confundida pela ideologia, ou um desconhecimento induzido pelas interdições; correspondem às exigências funcionais do discurso que deve produzir sua verdade".
}

Revista de Direito Brasileira | Florianópolis, SC | v. 26 | n. 10 | p. 5-24 | Mai./Ago. 2020 
nascimentos legítimos e ilegítimos, a precocidade e a frequência das relações sexuais, os efeitos do celibato, a eficácia das práticas contraceptivas, tudo com o fito de torná-las produtivas ou improdutivas consoante nos interesses do momento (FOUCAULT, 1988, p. 27/8). A sexualidade passa a ser também uma forma de controle de grupos, transcendendo seu aspecto individual e produtora de dados estatísticos. O sexo serve como princípio de regulação da vida da espécie.

De acordo com Fonseca (2012, p. 193/194), "todas as regularidades e as distorções, as constantes e as exceções pertinentes aos processos que são inerentes á população estão referidas no sexo". Nessa linha, a sexualidade se constitui como um produto de um mecanismo de saberpoder, na medida em que viabiliza discursos, práticas, técnicas, saberes e intervenções, porquanto o sexo é alvo de um investimento político maciço. Emerge, por conseguinte, uma preocupação sobre a maneira como cada indivíduo utiliza seu sexo e se comporta sexualmente, os quais são, concomitantemente, motivo de análise e ingerência. ${ }^{13}$ Mas "o que torna uma prática erótica boa e outra má? Trata-se de uma questão de ordem divina, natureza biológica ou convenção social?" (SPARGO, 2017, p. 11). As formas institucionais em que a sexualidade é socialmente aceita são resultados da escolha humana, cujos conflitos de interesse desencadeiam manobras políticas.

Como se pode depreender, então, sexo foi considerado identidade e caracterização dos indivíduos a partir de cientificidades biológicas elaboradas para a justificação de regimes de poder centrados unicamente na sua produtividade (BITTENCOURT, 2015, p. 231/2). Com efeito, tais "tecnologias do sexo" tinham o escopo de forjar uma população procriadora, que fosse capaz de fazer frente às necessidades (materiais e humanas) do sistema capitalista, centrado socialmente na respeitabilidade da família burguesa (SPARGO, 2017, p. 19).

Nesse contexto, surgem campanhas que visam deliberadamente transformar o comportamento sexual dos casais em uma conduta útil às diretrizes econômicas e/ou políticas (FOUCAULT, 1988, p. 29). São criadas várias políticas estigmatizantes do sexo sobre a vida, constituindo-se como verdadeiras estratégias de dominação: a histerização do corpo da mulher, a pedagogização do corpo da criança, a socialização das condutas de procriação e a psiquiatrização dos prazeres perversos. Resta claro nessa perspectiva o caráter repressivo da sexualidade, o qual visava a normalização e a utilidade dos corpos a fim de aparelhar uma economia peculiar (GUIZZO; INVERNIZZI, 2012, p. 124).

É nesse contexto que, de acordo com Foucault, "surge" a homossexualidade - não como prática, eis que as origens desse tipo de relação remontam o início da história humana, mas como categoria essencialmente problemática ${ }^{14}$, cuja pretensão era identificar uma "espécie" de indivíduo anômalo, vinculado a uma sexualidade perversa, a qual se tornou centro de estratégias que visavam a correção desse "desvio". Dentro da lógica exposta, as práticas sexuais entre pessoas do mesmo sexo não prestavam à formação de uma força de trabalho produtiva, constituindo-se em verdadeiras excrescências em relação à norma da procriação (SPARGO, 2017, p. 18/19).

Surge, nesse aspecto, a importância da psicanálise e da medicina para legitimar uma política sexualmente repressora, porquanto foram responsáveis por atribuir às sexualidades

\footnotetext{
13 Ressaltam-se as contribuições da escola e da psiquiatria, por exemplo, no investimento político sobre a pedagogização do sexo da criança, bem como o papel da ciência médica na especificação de diversas formas de sexualidades periféricas e na determinação de um prazer perverso. Observa-se a crescente atuação dos governos nas condutas de procriação, acarretando a responsabilização social dos casais quanto ao uso do seu sexo (FONSECA, 2012, p. 194).

${ }^{14}$ Insta ressaltar as modificações conceituais operadas em relação a determinadas categorias, a exemplo da própria noção de monstruosidade que, até então, era associada exclusivamente aos acidentes naturais da genética, mal formações congênitas, etc. Assim, de acordo com Fonseca (2012, p. 78): "a noção de monstruosidade que começa a se fixar a partir do final do século XVIII remete à ideia de irregularidade e distancia-se do caráter jurídico natural a que esteve ligada por tanto tempo, passando a concernir aos desvios de conduta de um indivíduo. Surge nesse momento a conduta do monstro moral, cuja monstruosidade é devida não propriamente a um erro da natureza, à desordem no seio das espécies, mas ao comportamento, como, por exemplo, a atração pervertida por pessoas do mesmo sexo".
} 
destoantes o caráter de patologia ou de perversão, conforme o caso (FOUCAULT, 1988, p. 119/121). Assim, além do sexo ser sobrecarregado de recomendações, tais eram de natureza jurídica, dando início à perseguição das sexualidades periféricas, tidas como desviantes, e - por óbvio - na categorização das pessoas de acordo com as suas "perversões". A ideia, socialmente aceita, de que toda sexualidade deveria estar submetida à lei - desautorizando qualquer forma de seu exercício que estivesse em desacordo com as prescrições legais - gera um autoritarismo repressivo, inclusive por parte de outros saberes.

O poder se caracteriza como um modo de agir predominantemente negativo, na medida em que tem a capacidade de excluir, sujeitar, recusar e interditar sob a forma da lei: em todas as instâncias "a forma geral do poder seria a forma geral do Direito, uma vez que aquele se definiria pelo jogo entre o lícito e o ilícito, a transgressão e o castigo" (FONSECA, 2012, p. 97/98). O Direito canônico, a pastoral cristã e a lei civil (além das recomendações advindas dos costumes e da opinião coletiva) passam a reger as práticas sexuais matrimoniais - haja vista que o sexo só era aceitável com finalidade reprodutiva, dentro do casamento heterossexual legítimo -, demarcando o que era proibido e o que era permitido (FOUCAULT, 1988, p. 38/42). De acordo com FOUCAULT (1988, p. 46), o poder seria, principalmente, "aquilo que dita a lei, no que diz respeito ao sexo. O que significa, em primeiro lugar, que o sexo fica reduzido, por ele, a regime binário: lícito e ilícito, permitido e proibido".

Destarte, não há como negar que a Biopolítica exerce seus efeitos sobre sexo, distinguindo e normalizando a população, em razão de uma contenda política. Há o controle sobre o aspecto mais íntimo do corpo ao se estabelecer juridicamente funções sexuais legítimas, e determinando os comportamentos válidos (e naturalmente opostos) para os signos femininos e masculinos. Adequam-se, dentro de um sistema binário que reconhece apenas duas performances possíveis, os papeis sociais de acordo com o modelo de sociedade previamente existente, estabelecendo focos de poder hierarquizado consoante a maior compatibilidade com a norma. Por meio do isolamento e da insistência na existência de sexualidades periféricas que as relações entre sexo e poder se solidificam e, por conseguinte, se multiplicam, esquadrinhando o corpo e entranhando-se às condutas. E, nessa cadência arranjada, as sexualidades são estancadas de acordo com uma faixa etária, "um lugar, um gosto, um tipo de prática. Proliferação de sexualidades por extensão do poder" (FOUCAULT, 1988, p. 47/48).

Destarte, se por um lado o sexo se insere nas disciplinas do corpo - adestramento, intensificação e distribuição das forças, ajustamento e economia das energias - de outra banda, se refere também à regulação das populações em razão de todos os desdobramentos que provoca. Desse modo, se faz presente nas vigilâncias sutis e meticulosas do quotidiano, fornecendo um micropoder sobre o corpo, e também em procedimentos de grande alcance, inserindo-se nas estatísticas e intervenções político econômicas que visam todo o corpo social ou, em determinados casos, grupos de pessoas com características comuns (FOUCAULT, 1988, p. 136).

Observa-se que a partir do século XVII, a sexualidade passou a ser reprimida na sociedade ocidental, bem como quaisquer discursos (orais e escritos) que versassem sobre ela. Tal repressão, contudo, não teve o condão de acabar com a sexualidade, mas escondê-la sob o manto do puritanismo burguês, constituindo-a sob origens históricas, sociais e culturais ao tempo em que se intitulava biológica e, dessa forma, diversas versões da confissão eram o centro dos instrumentos de internalização das normas sociais (SPARGO, 2017, p. 14/15).

Ocorre que tais políticas tiveram seu custo social, de modo que trouxeram consigo alguns dos mais cruéis preconceitos verificados ainda hoje: a discriminação sexual. Com efeito, a crença da heterossexualidade como característica do ser humano "normal" tem sua origem imbricada com os processos de normalização acima descritos, justificando que qualquer pessoa que extrapole os limites do padrão possa ser alocada como marginalizada, anormal ou patológica (DE JESUS, 2012, p. 29). A perspectiva foucaultiana desnaturalizou a sexualidade, explicitou o desejo como uma das possibilidades de controle e da normalização dos corpos e das subjetividades e destacou os vieses 
políticos e coletivos abrangidos na fixação das sexualidades normais, através da definição das periféricas (MISKOLCI, 2017, p. 85).

De fato, a partir do momento em que o Estado e o Direito ${ }^{15}$ passam a se interessar - regular e controlar - algo de esfera tão íntima e subjetiva quanto o sexo, a finalidade precípua passa a ser a promoção de uma sexualidade economicamente útil e politicamente conservadora por meio de controles pedagógicos e tratamentos médicos dos comportamentos sexuais desviantes, caracterizados como os que não se prestassem, por exemplo, a "assegurar o povoamento, reproduzir a força de trabalho, reproduzir a forma das relações sociais" (FOUCAULT, 1988, p. 36/7).

Percebe-se então a maleabilidade interpretativa dada à sexualidade, na medida em que foi utilizada para atribuir patologias a algumas pessoas, enquanto alçava outras à condição sexual ideal - a qual lhe outorgava, em consequência, uma posição social digna -, servindo como instrumento destinado à consecução de diversas estratégias políticas e econômicas por meio de coerção legal e moral. Há que se reconhecer, no entanto, que os efeitos dessa tecnologia política não se deram de forma homogênea na sociedade, uma vez que as repressões e interdições sexuais ocorreram de forma muito mais intensa sobre aquelas sexualidades que não se amoldavam aos objetivos estabelecidos pelo Estado. Ou seja, daqueles indivíduos que não se coadunam ao perfil cisgênero e heterossexual, por exemplo.

Diante disso, se o poder oprime pela lógica da censura, o sexo se constitui como elemento de inteligibilidade social do sujeito, eis que deve adotar uma postura adequada para ter acesso à totalidade do seu corpo. Tal perspectiva sem dúvida impacta na construção da identidade e na formação da personalidade dos indivíduos, haja vista que a docilidade dos corpos não acarreta apenas a sujeição, mas também na formatação dessas personalidades, cuja nefasta consequência é a inabilidade de se pensar em opções diversas das propostas disciplinares (ESTEVES, 2014, p. 302). Assim, houve uma política do sexo extremamente atuante na sociedade nos últimos dois séculos, cujas técnicas disciplinares tinham a finalidade de normalizar os indivíduos desde a infância.

\section{A CISNORMATIVIDADE COMO BIOPOLÍTICA DE GÊNERO: INVISIBILIDADE JURÍDICA DE CORPOS NÃO BINÁRIOS}

Quando o homem atribuía um sexo a todas as coisas, não via nisso um jogo, mas acreditava ampliar seu entendimento: - só muito mais tarde descobriu, e nem mesmo inteiramente ainda hoje, a enormidade desse erro. De igual modo o homem atribuiu a tudo o que existe uma relação moral, jogando sobre os ombros do mundo o manto de uma significação ética. Um dia, tudo isso não terá nem mais nem menos valor do que possui hoje a crença no sexo masculino ou feminino do Sol (Friedrich Nietzsche).

A espécie humana se insere no rol daquelas que ostenta uma reprodução sexuada, por isso ela tem dois "sexos" anatômica e fisiologicamente diversos, cuja principal função é a perpetuação da espécie por meio da reprodução. Ocorre que as sociedades contemporâneas supervalorizam essa diferenciação biológica, caracterizando os dois sexos com funções diferentes e usualmente hierarquizadas. Ademais, os padrões morais pré-estabelecidos pela sociedade definem como única possibilidade o sexo anatômico e funcionalizado, cujo escopo - para além da perpetuação da espécie- é a fixação de papeis sociais e da orientação sexual do indivíduo. Nessa visão simplista

\footnotetext{
15 Aqui, por fim, não se trata de esmiuçar uma inexistente pretensão foucaultiana de reescrever a história do Direito. Ao revés, apenas se reconhece as implicações recíprocas existentes na análise do biopoder e da governamentalidade, as diversas áreas do Direito e os mecanismos de normalização. Entende-se que as práticas e os saberes jurídicos sobretudo nas áreas do Direito Público, com ênfase para o Direito administrativo - têm o condão de servirem de vetores de normalização sobre a vida e seus processos (FONSECA, 2012, p. 230/231).
}

Revista de Direito Brasileira | Florianópolis, SC | v. 26 | n. 10 | p. 5-24 | Mai./Ago. 2020 
"os homens nascem com pênis e se relacionam sexualmente com mulheres, e mulheres nascem com vaginas e se relacionam com homens" (PAZÓ; SALLES; ZAGANELLI, 2015, p. 241).

Essa dicotomia - que, de acordo com Bourdieu (2014, p. 23), é uma construção direcionada a partir do protagonismo dado a algumas diferenças e, concomitantemente, do silenciamento a respeito de diversas semelhanças - origina uma das principais causas da desigualdade existente no mundo: a sexual. Nesse passo, baseada na distinção anatômica dos corpos e dos papeis sexuais ocupados (LOURO, 1997, p. 32), a constatação de características biológicas diversas sustenta grande parte das estruturas sociais responsáveis pela disseminação da opressão humana pelos seus semelhantes. Destarte, a construção social dos corpos e a divisão das atividades conforme a oposição entre masculino e feminino é inscrita em um sistema de oposição binária, iniciado pela lógica cartesiana.

\subsection{A construção de uma Biopolítica de gênero calcada em binarismos jurídicos}

O pensamento cartesiano alçou o homem (cisgênero, masculino, branco, heterossexual, europeu, proprietário, religioso) ao centro do mundo, estabelecendo-o como parâmetro de superioridade da humanidade em razão das suas capacidades racionais. Desde então, quaisquer diferenças biológicas, psicológicas ou sociais do modelo masculino eram interpretadas como deficiências e sinais de inferioridade (DOUZINAS, 2009, p. 111). A esse respeito, Foucault (1988, p. 96) afirma que a "atribuição da diferença está sempre implicada em relações de poder, a diferença é nomeada a partir de um determinado lugar que se coloca como referência". Logo, as relações sociais de sexo se moldaram, ao longo do processo histórico da humanidade, em oposição genuinamente hierarquizada. ${ }^{16}$

Com efeito, a tarefa de diferenciar homens e mulheres foi um viés importante do pensamento Iluminista, influenciando o modo como às ciências interpretaram as questões relacionadas ao sexo biológico, e cuja finalidade principal é oriunda do interesse de oferecer justificativas concretas para a pretensa inferioridade da mulher (SOUZA, CARRIERI, 2010, p. 50). A ciência exerceu, portanto, significativo papel, colaborando com a disseminação do preconceito ao "biologizar" o diferente ou as diferenças a fim de naturalizar uma inferioridade socialmente construída e atribuída ao grupo humano feminino. A ocorrência deste processo - baseado no determinismo biológico e sustentado pelo discurso científico - serviu como importante ratificação à ordem androcêntrica mundial (CUNHA BUENO, 2010, p. 12/3). Os corpos passam a assumir um significado cultural e, constituem um fundamento aparentemente natural da visão social da dominação masculina.

Não há como negar que o espectro de sociabilidade onde se desenvolvem os conceitos de masculino e feminino é permeado de disputas de visibilidade e, sobretudo, de poder, o qual produz e incita comportamentos conformados a um determinado padrão. Sob o ponto de vista foucaultiano, os sujeitos são classificados e hierarquizados conforme a aparência de seus corpos e forma de exercício da sua sexualidade, e essas características se transformam em marcas de poder (FOUCAULT, 1988, p. 98).

Ocorre que a lógica aplicada nas relações de poder é masculina, e o seu sujeito emerge como neutro e universal, cujo discurso (e a linguagem) dispensa a justificação, enquanto o feminino é apenas o reflexo dele, seu oposto inferior, autorizando a subalternização (BUTLER, 2017 p. 101). Essa diferenciação está calcada ainda na distinção biológica dos corpos, em que o corpo masculino é assumido como superior em razão da sua força, virilidade em oposição à passividade da maternidade, desempenhada pelo feminino. Ainda no aspecto biológico, diversos estudos médico-

\footnotetext{
${ }^{16}$ De acordo com Tamsin Spargo (2017, p. 36), a "oposição tradicional entre masculino e feminino, mutuamente dependente, porém antagônica, assumiu sua estrutura hierárquica por meio da associação com outras oposições: racional e emocional, forte e fraco, ativo e passivo".
} 
científicos colaboraram para sedimentar também uma inferioridade psíquica da mulher ao associar as suas doenças à expressão da própria natureza feminina, considerada instável e histérica.

Todavia, usar a anatomia para compreender as relações de poder entre homens e mulheres é insuficiente, na medida em que recai em biologicismos próprios do controle sobre os corpos, os quais foram calculados para direcionar as posturas humanas, desprezando os componentes históricos na construção desses papeis sociais. Com o passar do tempo percebeu-se que as concepções de masculino e feminino assumiram contornos que ultrapassam os limites do corpo, sendo concebidas também por meio do conceito de gênero, o qual é utilizado para designar as relações sociais entre os sexos, não se limitando apenas às especificidades físicas.

Assim, em resposta ao determinismo biológico que predominava no processo social de distinção entre sexos, o movimento feminista postulou a construção da noção de gênero a partir da década de 1970: embora a biologia divida a espécie humana entre machos e fêmeas, a maneira de ser homem e de ser mulher é expressa pela cultura e homens e mulheres são produtos da realidade social e não decorrência direta da anatomia de seus corpos. Gênero pode ser entendido como a construção social do masculino e do feminino e não comportamentos naturais decorrentes das diferenças entre sexos biológicos, na medida em que todos nós podemos adotar - cada qual à sua maneira - características e comportamentos considerados masculinos e femininos, independentemente do sexo biológico. Resta claro, pois, que não são apenas as características sexuais que definem uma pessoa enquanto masculino ou feminino, e sim - principalmente- a forma como essas características são representadas ou valorizadas em uma dada sociedade e em um determinado momento histórico (LOURO, 1997, p. 32).

Nesse aspecto, merece destaque a ressalva feita por Louro (1997, p 21/22), de que ao se ressaltar o caráter social da divisão não se pretende negar a existência da biologia e o fato de que o gênero se constrói sobre corpos sexuados. O que se contrapõe é o caráter essencialista atribuído à anatomia humana como condição inescapável da sua representação como homem ou mulher, de modo que o gênero deve ser compreendido como um processo de construção contínua e inacabada, distanciando-se de uma concepção imodificável e dada a priori. Destarte, o conceito de gênero passa a exigir "que se pense de modo plural, acentuando que os projetos e as representações sobre mulheres e homens são diversos" (LOURO, 1997, p. 23).

Logo, a categoria gênero expõe de forma mais acertada a construção social do corpo e a influência das tentativas normalizadoras sobre os sujeitos, e da Biopolítica sobre as populações. Dessa forma, gênero é uma importante divisão na análise que constitui as relações sociais por meio de uma estrutura de identidade pessoal (BITTENCOURT, 2015, p. 233). Evidente que a diferenciação entre os sexos é um instrumento político de reprodução social que viabiliza a validação velada das desigualdades. E, apenas quando se subtrai a naturalização atribuída ao gênero, tratando-o enquanto dado social que sofre os influxos políticos do local/época em que se insere é que será minimamente possível o distanciamento da dicotomia homem e mulher, admitindo-se "que há inúmeras formas de expressar a condição de gênero e diversos modos de interligar a relação corpo/sexo/gênero" (PAZÓ; SALLES; ZAGANELLI, 2015, p. 245).

Infelizmente, todavia, a lógica de dominação masculina - ao reafirmar a oposição binária que envolve a classificação de gênero apenas em masculino e feminino - se impõe sobre todas as outras formas de identidade de gênero ${ }^{17}$ que destoam do par disjuntivo padrão, negando-lhes qualquer forma de visibilidade, reconhecimento e, consequentemente, concessão de direitos que possam tutelar sua existência. E uma das implicações mais expressivas da desconstrução da dicotomia sexista está na perspectiva de compreensão - e aceitação - de outras formas de masculinidade e feminilidade que se constituem socialmente.

O binarismo é uma "crença, construída ao longo da história da humanidade, em uma dualidade simples e fixa entre indivíduos dos sexos feminino e masculino" (DE JESUS, 2012, p.

\footnotetext{
${ }^{17}$ A identidade de gênero se refere à autoconstrução do sujeito referenciada no sistema binário culturalmente instituído homem/mulher, a partir da qual há o "desejo de comunicar" uma identidade.
}

Revista de Direito Brasileira | Florianópolis, SC | v. 26 | n. 10 | p. 5-24 | Mai./Ago. 2020 
28), que ignora a complexidade das interações sexuais humanas e, desta forma, invalida as experiências que se afastem dessa lógica. Não há que se olvidar, ainda, que a problemática da hierarquia sexual incutida com os binarismos jurídicos está inscrita também num contexto de rigidez social e num cenário heteronormativo ${ }^{18}$, disciplinadores da constituição da família e da própria sexualidade dos indivíduos. Nesse aspecto, Butler (2017, p. 43) enfatiza que a relação entre sexo/gênero/desejo aparece como linear e causal entre tais categorias, porquanto o indivíduo deve obrigatoriamente adotar características de gênero que sejam compatíveis com seu sexo biológico e, ainda, seu desejo sexual deve ser orientado ao sexo oposto.

O entendimento dos gêneros dentro dessa ofuscada visão binária se traduz em polos contrapostos, trazendo consigo possibilidades únicas de masculinidade e de feminilidade e todos os sujeitos sociais que não se "enquadram" em uma dessas formas - impostas pela homogeneização social a partir da disciplina - são negados ou ignorados social e juridicamente. Com efeito, essa é a realidade vivenciada por pessoas que não se identificam com o seu sexo biológico, a exemplo dos transgêneros ${ }^{19}$, e daqueles que não se identificam, definitivamente, com nenhum gênero, os não binários, dentre outras possibilidades tidas como "sexualidades desviantes"(BUTLER, 2017, p. 25/28).

A esse respeito, transexualidade é a condição sexual da pessoa que "rejeita sua identidade genética e a própria anatomia de seu gênero, identificando-se psicologicamente com o gênero oposto. Trata-se de um drama jurídico-existencial, por haver uma cisão entre a identidade sexual física e psíquica" (DE JESUS, 2012, p. 30). Em contrapartida, não-binário é uma pessoa cuja identidade de gênero não pertence nem ao masculino nem ao feminino, está entre as (ou além das) classificações de gênero, ou pertence a alguma combinação de gêneros. Essa identidade é normalmente relacionada a uma reação às construções sociais de gênero, aos estereótipos e ao sistema binário de gênero (DE JESUS, 2012, p. 32).

Destarte, a redução do espectro de possibilidades do exercício da sexualidade humana pela dualidade binária, que admite apenas a relação direta entre o sexo biológico e o gênero, traz consigo o cissexismo que, praticado em âmbito institucional, dificulta o direito de autoexpressão de gênero das pessoas, "criando mecanismos legais e culturais de subordinação das pessoas cisgênero e transgênero ao gênero que lhes foi atribuído ao nascimento. Para as pessoas trans em particular, o cissexismo invisibiliza e estigmatiza suas práticas sociais” (DE JESUS, 2012, p. 28), obstaculizando uma existência digna.

Nesse sentido, cabe mencionar os efeitos -sociais, jurídicos, identitários, etc - da Biopolítica ainda presentes no mundo contemporâneo. A técnica da normalização por meio da patologização de comportamentos atinge hoje milhares de pessoas cuja identidade é considerada pela medicina como transtorno psiquiátrico. A título de exemplo, a identidade transgênero era- até meados de 2018 - denominada de "transtorno de identidade de gênero" (TIG), e classificada pelo CID-10 (Classificação Internacional de Doenças da Organização Mundial de Saúde) ${ }^{20}$ e no DSM-

\footnotetext{
${ }^{18}$ Entenda-se por heteronorma um construto teórico baseado na conceituação da visão que identifica que "a 'coerência' e 'continuidade' da 'pessoa' não são aspectos lógicos ou analíticos da personalidade mas, ao invés disso, normas de inteligibilidade socialmente instituídas e mantidas. Da mesma forma que a 'identidade' é assegurada através dos conceitos estabilizadores do sexo, gênero e sexualidade, a própria noção de 'pessoa' é posta em questão pela emergência cultural dos seres generificados de maneira 'incoerente' e 'descontínua', que parecem ser pessoas, mas que falham em conformar-se às normas gendradas de inteligibilidade cultural pelas quais as pessoas são definidas" (BUTLER , 2017. p. 23)

${ }^{19}$ Aqui importa diferenciar os conceitos de transgênero e transexual, os quais não se confundem, na medida em que transexual designa aquelas pessoas que se submeteram a "tratamentos médico, incluindo procedimentos cirúrgicos e hormonais, para fazer com que o corpo corresponda à percepção que a pessoa tem de si mesma como homem ou mulher. Já o transgênero se refere às pessoas que rechaçam as normas culturais de aparência ou comportamento masculino e feminino e sua suposta correspondência com uma masculinidade ou feminilidade biológica preexistente" (SPARGO, 2017, p. 54).

${ }^{20}$ A CID é uma codificação padronizada de todas as doenças, distúrbios, condições e causas de morte. Essa norma serve para que os países obtenham dados estatísticos e epidemiológicos sobre sua situação sanitária e possam planejar

Revista de Direito Brasileira | Florianópolis, SC | v. 26 | n. 10 | p. 5-24 | Mai./Ago. 2020
} 
IV-R (Manual de Diagnóstico e Estatísticas de Distúrbios Mentais da Associação Psiquiátrica Americana - APA). ${ }^{21}$

Ainda, no âmbito nacional, de acordo com a Resolução n 1955/2010 do Conselho Federal de Medicina (BRASIL, 2010), o sujeito transexual é aquele que é diagnosticado com a disforia de gênero, definido como "portador de desvio psicológico permanente de identidade sexual, com rejeição do fenótipo e tendência à automutilação e/ou autoextermínio". Com efeito, a denominada disforia de gênero é classificada como um transtorno psíquico, passível de procedimento terapêutico (PAZÓ;SALLES; ZAGANELLI, 2015, p. 243).

Observa-se que através de uma ciência mundialmente difundida, ainda se perpetuam os mecanismos de controle do corpo das pessoas pela insistência da reprodução do binômio único. Legitimar as leis e as práticas sociais que constrangem a pluralidade de existências implica em uma chancela coletiva à invisibilidade dessas pessoas, optando-se por um caminho único que não tenha o condão de ameaçar o dogma político da exclusividade de apenas duas "formas de ser e sentir" o mundo. Resta indubitável que a patologização da transexualidade - sob o termo "transtorno de identidade sexual" - é uma forma cruel de controle e normalização (REDE INTERNACIONAL PARA A DESPATOLOGIZAÇÃO TRANS, s.d).

Nesse cenário opressivo e limitado, o indivíduo está condicionado à passividade, de modo que seu corpo passa a ser um instrumento para a manifestação de um "gênero inteligível" - definido por BUTLER (2017, p. 38) como sendo aquele que "mantém relações de coerência e continuidade entre sexo, gênero, prática sexual e desejo". Assim, as identidades de gênero "não-inteligíveis" as que contém em seu cerne discrepâncias com a matriz binária heterossexual e cisnormativa vigente-, materializadas na não-correlação entre sexo/gênero/desejo - são automática e repetidamente desconsideradas, invisibilizadas social e juridicamente.

Essa reprodução, pela sociedade e, especialmente, por juristas, automática e acrítica de lógicas que evocam a discriminação em seu cerne, contribui para a manutenção de práticas que geralmente estão dissociadas da realidade em que foram construídas, mas acarretam a perpetuação de ideologias - em regra, preconceituosas e limitadoras da própria identidade individual.

\section{2 (In) visibilidade jurídica dos corpos que (não) importam}

O viés interpretativo conservador da teoria tradicional objetiva manter o status quo de uma sociedade machista, patriarcal e patrimonializada, neutralizando as disputas de poder que envolvem a construção dos elementos identitários destoantes do padrão determinado como "normal". Essa lógica é naturalizada em simbolismos presentes na sociedade e, inclusive, institucionalizada por meio do Direito, resultando em violências reais e simbólicas por parte dos particulares e do Estado. Dessa forma, o discurso hegemônico gera zonas de ininteligibilidade em razão da criação arbitrária de categorias identitárias fechadas, impactando na construção de um discurso delimitador que é refletido na marginalização de determinadas pessoas em relação aos sujeitos enquadrados pela norma do gênero binário. 
Nessa perspectiva, a identidade de gênero acaba se constituindo em um instrumento de poder e conformidade que atravessa o Direito (MARTINS, 2012, p. 50).

O poder fabrica sujeitos, define identidades e cria categorias (como gênero e sexualidade) identitárias que são efeitos das instituições, práticas e discursos (TONELI; BECKER, 2010, p.5). Evidente, pois, que a sexualidade assume relevância nos processos de invisibilização normativa, haja vista que embora seja socialmente regulada e condicionada, sua regulação social é escondida da visão coletiva, assumindo caráter de naturalidade biológica. A invisibilidade dessa regulação acarreta a invisibilidade jurídica das pessoas, pois a crítica e desconstrução daquilo que está abstratamente consolidado na sociedade se torna infinitamente mais difícil, uma vez que suas premissas aparecem como algo que sempre existiu (formação imemorial da cultura) ou divinamente estabelecido sendo, portanto, inquestionáveis e apropriadas.

Ademais, a opressão como forma de invisibilização traduz uma recusa à existência legítima, pública, conhecida e reconhecida, sobretudo pelo Direito, decorrente dessa estigmatização velada, de forma que sua contestação se mostra ainda mais difícil (BORDIEU, 2014, p.144). Tal realidade ganha ainda mais relevância a partir da verificação de que a organização da modernidade pressupõe o conceito de direitos, eis que por meio deles se podem expressar as necessidades individuais, formuladas por meio de demandas. Sob essa perspectiva, os direitos têm como função primeira a de construir a pessoa individual como um sujeito (jurídico), e os direitos não apenas pertencem aos seres humanos, ao contrário, fabricam-nos, ao dotá-los dos poderes e capacidades concretas por meio dos quais eles podem concretizar seu livre-arbítrio: quanto mais direitos se tem, mais humano se é (DOUZINAS, 2009, p. 266/267).

Ocorre que nem todas as pessoas são igualmente "sujeito de direitos" e, dessa forma, a heteronormatividade disciplina o entendimento coletivo de gênero, estruturando os mundos social, político e jurídico. Ao forjar crenças e valores e incutir efeitos tangíveis nas instituições, leis e vida cotidiana - a exemplo de questões previdenciárias, patologização de identidades, condições de cárcere, casamento, adoção, até questões aparentemente banais como a identificação civil e o uso de banheiros - essa lógica cria entraves por vezes insuperáveis à fruição da dignidade humana dessas pessoas, por meio da estigmatização, marginalização e invisibilização. Em contrapartida, privilegia aqueles que mais se aproximam do padrão. É “a violência normativa que permite que o sujeito se submeta às violências do dia-a-dia, assim como a invisibilidade destas" (TONELI; BECKER, 2010).

Depreende-se do exposto que, dia após dia, os transexuais, não binários, gênero fluído, dentre outras sexualidades "desviantes" enfrentam dificuldades em decorrência da ausência de leis específicas que tutelem a sua singularidade enquanto indivíduo, bem como da falta de políticas públicas adequadas. As referidas lacunas estatais em relação à regulação dos efeitos jurídicos da transexualidade reforçam o desamparo dessas pessoas. Essas omissões repercutem em violências simbólicas, eis que insuflam uma realidade heterossexual e heterossexista que punem os dissidentes e reforçam as técnicas de normalização (SILVEIRA; BIANCHINI; MARCHETTO, 2015, p. 76). A esse respeito, BUTLER (2017, p. 191) afirma que:

É somente a partir de uma posição conscientemente desnaturalizada que podemos ver como a aparência de naturalidade é ela própria constituída. Nossas pressuposições sobre os corpos sexuados, sobre o fato de serem um ou outro, sobre os significados que lhe são considerados inerentes ou decorrentes de serem de tal ou qual modo sexuados, se veem repentina e significativamente perturbadas por esses exemplos, que não concordam com as categorias que naturalizem e estabilizam esse campo dos corpos para nós nos termos das convenções culturais vigentes. Consequentemente, é o estranho, o incoerente, o que está "fora da lei" que nos dá uma maneira de compreender o mundo inquestionado da categorização sexual como um mundo construído, e que certamente poderia ser construído diferente. 
Não há que se olvidar, portanto, que a igualdade não foi, nem ao menos timidamente, efetivada na sociedade hodierna. Consoante Clara Moura Masiero (2018, p. 85), há uma convivência acrítica e passiva com panoramas de sujeição homogeneizadores, que contribuem na supressão das diferenças pessoais e obstaculizam a fruição da dignidade humana de determinados grupos sociais, cuja eternização ao longo da história se traduz em uma forma particular de violência social: a violência normativa decorrente do preconceito.

Todavia, a constituição identitária própria - livre de (pré) formatações e limitações - é absolutamente vital aos grupos sociais marginalizados por um preconceito comum, sobretudo quando oriundo do próprio Estado e reproduzido pelo sistema jurídico. Nesse aspecto, Bauman (2005, p. 44) afirma que a estratificação de identidades é sustentada pela identificação dos indivíduos ao conceberem-nas apenas na sua dimensão diferenciadora. Em um lado da hierarquia social se encontram aqueles que articulam suas identidades à própria vontade. Do outro lado, contudo, são espremidos aqueles que tiveram a escolha da identidade negada, que são proibidos de manifestar suas preferências e que, ao cabo, são oprimidos pela imposição de identidades estereotipadas, humilhantes, desumanizadoras e estigmatizantes, das quais eles próprios se ressentem sem, contudo, terem a possibilidade de abandoná-las.

Infelizmente, contudo, a marginalidade social de tais minorias não cessa somente com o almejado reconhecimento de direitos e a sua alçada à condição de sujeito, na medida em que sob elas ainda paira a opressiva influência da pecha normalizadora que persiste no meio social, eternizado o estigma. Faz-se necessária uma verdadeira transformação nas bases sociais, com a ressignificação de posições, categorias e identidades. Insta salientar, ainda, que a transformação social visada com a desconstrução da binariedade de gênero possui efeitos benéficos que transcendem a própria realidade individual daqueles que a ela não se compatibilizam, como transgêneros e não binários, impactando também na vida de todos que se encontram inferiorizados em razão da existência da heteronorma. Isso se dá em razão do fato de que a exclusão e as violências geradas por um sistema de categorização desigual de pessoas alcançam diversos segmentos da sociedade, cuja ideologia e técnicas da Biopolítica e da disciplina normalizadora exercem suas finalidades de hierarquizar e excluir sujeitos (MARTINS, 2012, p. 50).

Todavia, posteriormente a exclusão dos "anormais" precisa ser minimizada em forma de intensas lutas sociais, a fim de afastar os paradigmas de conduta que inserem as noções de normalidade e reforçam a ideia da existência do homem médio. Impende reconhecer a existência de uma dicotomia, que coloca o Direito tanto como causa quanto solução dos processos de marginalização social, mormente pela concessão de posições jurídicas àqueles que estão à margem do sistema. Tal descompasso, por conseguinte, mina a confiança depositada no sistema jurídico enquanto ferramenta de resistência à opressão, sendo visto ao longo do tempo como mecanismo de dominação do homem pelo homem (ESTEVES, 2014, p. 321).

Assim, se a prescrição de regras de conduta é um traço inerente à norma jurídica, se faz indispensável que o Direito não se descuide da sua propensão de desencadear processos de normalização, os quais numa sociedade cada vez mais complexa e plural se mostram descabidos. Logo, o sistema jurídico deve ser objeto de contínua inquietação, com a constante discussão de suas premissas, a fim de que tenha a aptidão de servir como mecanismo de rechaço à governamentalidade, calcado na indocilidade dos indivíduos, os quais afastam sua submissão à norma quando atuar como procedimento de normalização (ESTEVES, 2014, p. 321).

Entende-se que somente dessa forma poderia haver a construção de um poder com características positivas: de criação de novas subjetividades e emancipação pessoal dos sujeitos correspondentes. Nesse sentido, FOUCAULT (2008, p. 479) aduz que:

[...] deve haver um momento em que a população, rompendo com todos os vínculos de obediência, terá efetivamente o direito, não em termos jurídicos, mas 
em termos de direitos essenciais e fundamentais, de romper todos os vínculos de obediência que ela pode ter com o Estado e, erguendo-se contra ele, dizer doravante: é minha lei, é a lei das minhas exigências, é a lei da minha própria natureza de população, é a lei das minhas necessidades fundamentais que deve substituir essas regras da obediência.

Por fim, pode-se pensar com Foucault a emergência de um poder que "constrói; destrói e reconstrói; que transforma, acrescenta, diminui, modifica a cada momento e em cada lugar a si mesmo e a cada coisa com a qual se relacione em uma rede múltipla, móvel, dinâmica, infinita" (POGREBINSCHI, 2004, p. 198). Abre-se, então a perspectiva do poder como autogoverno, um cuidado de si que autocapacita como um instrumento de resistência à pretensão de governabilidade dos corpos e, portanto, faculta o seu titular - finalmente - ao gozo de uma existência plena e digna, através do exercício livre de sua sexualidade e identidade.

\section{CONCLUSÃO}

A construção de práticas sexuais individuais e da identidade de gênero livre dos efeitos estigmatizantes da normalização, do poder disciplinar e da exclusão dos que a ela não se formatam, demandam o respectivo acompanhamento nas estruturas jurídicas e sociais nas quais estão inseridas, sob pena do Direito se tornar obsoleto ou, pior, um obstáculo intransponível às novas formas de se relacionar e de se posicionar como sujeito diante do mundo.

A esse respeito, a proteção jurídica da identidade de gênero- enquanto faceta importante da individualidade humana e desenvolvida como alvo de poder e de disputa social - possui especial relevância, na medida em que a sua opressão em razão da existência de padrões de sexualidade acarreta na perpetuação de técnicas de controle dos corpos, os quais servem a interesses políticos e econômicos.

Nesse aspecto, é imprescindível que sejam publicamente descortinados os sutis mecanismos de opressão sexual intencionalmente desenvolvidos ao longo dos séculos, cuja aparente ligação apenas com os aspectos biológicos do corpo humano naturaliza as hierarquias de valor socialmente construídas, impondo uma perspectiva estanque de possibilidades existenciais e sancionando moral, social e juridicamente os elementos não docilizados pela coerção normativa.

A ressignificação do poder inscrito na sexualidade impende que o Direito possa ser usado também como resistência à normalização do indivíduo ou da população, e a alteração do paradigma de desvalorização de modos diferentes de ser possa ser dar por meio do respeito pelo valor equivalente que todos possuem enquanto seres humanos, sem que tenham suas particularidades aniquiladas pela finalidade homogeneizante dos corpos, orientados para uma prática economicamente rentável e politicamente conservadora.

É, então, por meio das tensões morais originadas por situações de desrespeito que se forjam as lutas quotidianas por mudanças sociais e jurídicas. É também no seio da insatisfação popular com as injustiças ou omissões, que os direitos se constroem: sempre em um processo dialógico e inacabado, constituído por e para pessoas reais, objetivando proteger e dignificar existências, ainda - e principalmente - que não sejam elas as "normais". 


\section{REFERÊNCIAS}

AGAMBEN, Giorgio. Estado de exceção. Tradução de Iraci D. Poleti. $2^{a}$ ed. São Paulo: Boitempo, 2004.

BAUMAN, Zygmunt. Identidade: entrevista a Benedetto Vecchi. Rio de Janeiro: Jorge Zahar Editores, 2005.

BITTENCOURT, Naiara Andreoli. A biopolítica sobre a vida das mulheres e o controle jurídico brasileiro. Periódico do Núcleo de Estudos e Pesquisas Sobre Gênero e Direito, João Pessoa, v. 3, p.225-245, nov. 2015. Disponível em: http://periodicos.ufpb.br/ojs2/index.php/ged/index. Acesso em: 27 fev. 2019.

BORDIEU, Pierre. A Dominação Masculina. 12. ed. Rio de Janeiro: Bertrand Brasil, 2014.

BRASIL. Resolução $\mathrm{n}^{\circ} 1955$, de 03 de setembro de 2010. Dispõe sobre a cirurgia de transgenitalismo e revoga a Resolução CFM nº 1652/2002. Brasília: Conselho Federal de Medicina, [2010]. Disponível em:

http://www.portalmedico.org.br/resolucoes/CFM/2010/1955_2010.htm. Acesso em: 03 fev. 2019.

BUTLER, Judith. Problemas de gênero: feminismo e subversão da identidade. Trad Renato Aguiar. 15ª ed. Rio de Janeiro: Civilização Brasileira, 2017.

CUNHA BUENO, Mariana Guimarães Rocha da. Feminismo e Direito Penal. Orientador: Renato de Mello Jorge Silveira. Dissertação de Mestrado. PPG em Direito Penal. USP: São Paulo, 2011. Disponível em:

https://www.google.com.br/url?sa=t\&rct=j\&q=\&esrc=s\&source=web\&cd=1\&cad=rja\&uact=8\& ved=0CB0QFjAA\&url=http $\% 3 \mathrm{~A} \% 2 \mathrm{~F} \% 2 \mathrm{Fwww}$.teses.usp.br\%2Fteses $\% 2 \mathrm{Fdisponiveis} \% 2 \mathrm{~F} 2 \% 2 \mathrm{~F}$ $2136 \% 2$ Ftde-14052012-

161411\%2Fpublico\%2FMariana_Guimaraes_Rocha_da_Cunha_Bueno_ME.pdf\&ei=dKZiVa7L G4GUNv2lgcgK\&usg=AFQjCNFK1z-

mYDc8ml7z0ZTEyHAHIvluiA\&sig2=OYFH2OnlBYakGdU3iT_uRw\&bvm=bv.93990622,d.eX Y. Acesso em: 28 de mar. de 2019.

DE JESUS, Jaqueline Gomes. Orientações sobre Identidade de Gênero: Conceitos e Termos. $2^{\mathrm{a}}$ ed. Brasília: Fundação Biblioteca Nacional, 2012. Disponível em: http://www.diversidadesexual.com.br/wp-content/uploads/2013/04/G\%C3\%8ANEROCONCEITOS-E-TERMOS.pdf. Acesso em: 12 mar. 2019.

DOUZINAS, Costas. O fim dos Direitos Humanos. São Leopoldo, Editora Unisinos, 2009.

ESTEVES, Marcos Guilhen. O sentido de norma em Foucault e o papel do direito na produção de corpos dóceis. In: Publicações do XXIII Encontro Nacional do Conselho Nacional de Pesquisa e Pós graduação em Direito, 2014, João Pessoa. p. 298 - 323. Disponível em:

http://publicadireito.com.br/publicacao/ufpb/livro.php?gt=140. Acesso em: 26 mar. 2019.

FONSECA, Márcio Alves da. Michel Foucault e o Direito. 2a ed. São Paulo: 2012.

FOUCAULT, Michel. Microfísica do Poder. 12. ed. Rio de Janeiro: Graal, 1979. 
FOUCAULT, Michel. A história da sexualidade I: A vontade de Saber. 13. ed. Rio de Janeiro: Graal, 1988.

FOUCAULT, Michel. Em defesa da sociedade. São Paulo: Editora Martins Fontes, 1999.

FOUCAULT, Michel.Segurança, território, população: curso dado no Collège de France (19781979). São Paulo: Martins Fontes, 2008.

FOUCAULT, Michel. .Vigiar e Punir: Nascimento da Prisão. 38 ed. Petrópolis: Vozes, 2010.

GUIZZO, Daniele Cristina; INVERNIZZI, Noela. A potencialização das práticas biopolíticas pela tecnologia: novas produções do corpo e gênero feminino. Revista Ártemis, João Pessoa, v. 13, p.119-128, 2012. Disponível em: http://www.periodicos.ufpb.br/ojs/index.php/artemis/article/view/14217/8204. Acesso em: 28 abr. 2018.

LOURO, Guacira Lopes. Gênero, sexualidade e educação: uma perspectiva pós estruturalista. Petrópolis: Vozes, 1997.

MARTINS, Daniel Fauth. Disciplina, biopolítica e violência no paradigma do gênero binário: o papel da política criminal no enfrentamento da violência contra pessoas trans. Orientador: Paulo César Busato. 2012. 63 f. Monografia (Graduação) - Curso de Direito, Setor de Ciências

Jurídicas, Universidade Federal do Paraná, Curitiba, 2012. Disponível em: https://acervodigital.ufpr.br/handle/1884/31249. Acesso em: 27 abr. 2019.

MASIERO, Clara Moura. Mobilização do direito e enfrentamento ao preconceito: os movimentos feminista, negro e LGBTQ e a constituição de 1988. Revista de Direito Brasileira, São Paulo, v. 8, p.84-107, dez. 2018. Disponível em: file:///C:/Users/Isadora/Downloads/4117-15352-1PB.pdf. Acesso em: 09 abr. 2019.

MISKOLCI, Richard. Estranhando Foucault: uma releitura queer da história da sexualidade I. In: Foucault e a Teoria Queer. Belo Horizonte: Autêntica Editora, 2017.

NIETZSCHE, Friedrich. Aurora. São Paulo: Escala, 2008.

POGREBINSCHI, Thamy. Foucault, para além do poder disciplinar e do biopoder. Lua Nova, Rio de Janeiro, n. 63, p.179-201, 2004. Disponível em: http://www.scielo.br/pdf/ln/n63/a08n63.pdf. Acesso em: 10 mar. 2019.

REDE INTERNACIONAL PARA A DESPOLITIZAÇÃO TRANS. Manifesto. Disponível em: < http://www.stp2012.info/old/pt/manifesto> Acesso em: 12 abr. 2019

SILVEIRA, Marina; BIANCHINI, Guilherme Correa; MARCHETTO, Patricia Borba. Nascidos livres e iguais: a implementação de Política Pública de Lei de Identidade de Gênero como mecanismo de reconhecimento social e jurídico da transexualidade. Temas de Administração Pública, Araraquara, v. 10, n. 2, p.73-86, 2015. Disponível em:https://webcache.googleusercontent.com/search?q=cache:LNXiwgFOFR8J:https://periodicos. fclar.unesp.br/temasadm/article/download/11795/7608+\&cd=1\&hl=pt-BR\&ct=clnk\&gl=br. Acesso em: 13 abr. 2019. 
SIQUEIRA, Carlos Eduardo Pereira; BIGOLIN NETO, Pedro. O estado de Direito e Sociedade de normalização: Estudos Focaultianos. In: I Congreso Latinoamericano de Teoría Social. Instituto de Investigaciones Gino Germani. Facultad de Ciencias Sociales, Universidad de Buenos Aires, Buenos Aires, 2015. Disponível em: http://cdsa.aacademica.org/000-079/70.pdf. Acesso em: 28 abr. 2018.

SOUZA, Eloisio Moulin de; CARRIERI, Alexandre de Pádua. A analítica queer e seu rompimento com a concepção binária de gênero. Ram. Revista de Administração Mackenzie, [s.1.], v. 11, n. 3, p.46-70, jun. 2010. Disponível em:

http://www.scielo.br/pdf/ram/v11n3/a05v11n3.pdf. Acesso em: 02 abr. 2019.

SPARGO, Tamsin. Foucault e a teoria queer. Belo Horizonte: Autêntica Editora, 2017.

TONELI, Maria Juracy Filgueiras; BECKER, Simone. A violência normativa e os processos de subjetivação: contribuições para o debate a partir de Judith Butler. Fazendo Gênero 9: Diásporas, Diversidades, Deslocamentos. Santa Catarina, ago. 2010. p. 1-8. Disponível em:

http://www.fazendogenero.ufsc.br/9/resources/anais/1278169629_ARQUIVO_Trabalhocompleto MJFTeSBAviolencianormativa.pdf. Acesso em: 23 mar. 2019.

WOLKMER, Antonio Carlos. Fundamentos da história do Direito. Belo Horizonte: Del Rey, 2006. 